\title{
Are Cultural Characteristics Associated With the Relationship Between Self and Others' Ratings of Leadership?
}

\author{
Leanne Atwater \\ University of Houston \\ James W. Smither \\ La Salle University
}

\author{
Mo Wang \\ University of Maryland \\ John W. Fleenor \\ Center for Creative Leadership
}

\begin{abstract}
This study examined the relationship between self and subordinate ratings of leadership and the relationship between self and peer ratings of leadership for 964 managers from 21 countries. Using multilevel modeling, the authors found that cultural characteristics moderated the relationship between self and others' ratings of leadership. Specifically, the relationship between self and subordinate ratings, as well as between self and peer ratings, was more positive in countries that are characterized by high assertiveness. The relationship between self and subordinate ratings, as well as between self and peer ratings, was also more positive in countries characterized by high power distance. The authors also found a leniency bias in individualistic cultures for self, peer, and subordinate ratings. In sum, cultural characteristics should be considered in attempts to understand relationships between self and other ratings.
\end{abstract}

Keywords: leadership, self-other agreement, culture

Research on managerial self-awareness, defined as the degree to which managers see themselves as others see them (Wohlers \& London, 1989), has concluded that self-awareness is related to more positive individual and organizational outcomes (cf. Yammarino \& Atwater, 1993). Kruger and Dunning (1999) as well as Ashford (1989) argued that self-ratings that overestimate one's skills or abilities are doubly burdensome because people not only make poor choices but they are also often unaware of them.

Managerial self-awareness is most often studied by examining the relationship between a manager's self-ratings and ratings from others (e.g., direct reports, supervisor, or peers). Research has shown that self-ratings are unrelated or only weakly related to ratings made by others (Harris \& Schaubroeck, 1988; Mabe \& West, 1982). This finding has been observed regardless of whether ratings were being made on performance, skills, behaviors, or traits. In sum, managerial self-awareness is important, yet many individuals lack this self-awareness. Attempts to understand the factors that contribute to this deficiency are beginning to emerge. For example, a few studies have looked at demographic variables such as age, race, and gender as possible antecedents of the

Leanne Atwater, Department of Management, University of Houston; Mo Wang, Department of Psychology, University of Maryland; James W. Smither, Lindback Professor of Human Resource Management, La Salle University; John W. Fleenor, Psychometrics, Global Research, Center for Creative Leadership, Greenboro, North Carolina.

We thank Mary Sully de Luque, Fran Yammarino, Phillip Braddy, and Cheri Ostroff for their helpful comments concerning this article.

Correspondence concerning this article should be addressed to Leanne Atwater, Department of Management, University of Houston, 334 Melcher Hall, Houston, TX 77204-6021. E-mail: leatwater@uh.edu relationship between self and others' ratings (cf. Brutus, Fleenor, \& McCauley, 1999; Ostroff, Atwater, \& Feinberg, 2004; Wohlers, Hall, \& London, 1993).

The social environment in which individuals live and work may also serve as a possible antecedent of the relationship between self and others' ratings. Self and others' ratings depend in part upon interpersonal interactions and feedback shared (Ashford, 1989). This suggests that cultural differences that influence the social environment could be relevant. Bailey, Chen, and Dou (1997) suggested that "culture affects individual desire for, behavior toward and perception of performance feedback" (p. 619). This indicates that whether feedback is sought or taken seriously may vary as a function of culture. In turn, how feedback is perceived and how it is attended to are likely to affect the relationship between self and others' ratings of behavior or performance.

The globalization of work and the recent expansion of multisource feedback to organizations outside the United States prompted us to question whether results found in U.S. organizations are generalizable to other cultures. Cultural characteristics might help us understand the relationship between self and others' ratings. However, most studies that have examined self and others' ratings have taken place in the United States on American samples, where cultural norms are relatively consistent. Thus, the potential influence of cultural differences on the relationship between self and others' ratings has not been addressed.

We examined whether the relationship between leaders' selfratings and ratings provided by their followers (or peers) is moderated by cultural variables. The relationship between self-ratings and others' ratings is of particular interest in applied settings in which rank ordering the effectiveness of leaders (which leaders are best and which are worst) is especially important for decision- 
making purposes (e.g., which leaders are ready for promotion, which deserve a large bonus). Understanding the relationship between leaders' self-ratings and ratings from their followers (or peers) can help us understand whether using follower (or peer) ratings to rank order leaders would yield the same relative rank order as using leaders' self-ratings.

We use the framework devised by Aycan and Kanugo (2001), which suggests that environmental context (including sociocultural context) influences behavioral and interpersonal characteristics (such as communication and leadership/managerial practices), which in turn influence individual outcomes (such as performance, effectiveness, and organizational attitudes). In the current study, we predicted that cultural context would influence the nature of verbal and nonverbal communication, which would then affect the clarity, candor, and accuracy of interpersonal feedback and hence the relationship between leaders' self-ratings and ratings from their followers and peers. We could anticipate, for example, that communication patterns that are known to differ in various cultures (Gelfand, Erez, \& Aycan, 2007) would affect the relationship between self and others' ratings. For instance, when behaviors, strengths, weaknesses, and problems are openly discussed by leaders, followers, and peers, we would expect leaders to have more information on which to rate themselves and that those ratings would more closely correspond to ratings made by others.

Gelfand et al. (2007) in their report on cross-cultural organizational behavior in the Annual Review of Psychology suggested that future research should explore further why cross-cultural differences exist and move beyond emphasis on individualism and collectivism. We focused on a set of specific cultural context variables that we believe influence communication patterns and in turn the ways leaders, their subordinates, and their peers evaluate the leader's leadership behaviors. The variables we have chosen were taken from the well-known Global Leadership and Organizational Behavior Effectiveness (GLOBE) study (House, Hanges, Javidan, Dorfman, \& Gupta, 2004). The purpose of GLOBE was to increase available knowledge about cross-cultural interactions. The data collected included 17,000 responses from managers in 951 organizations in 62 societies. The resulting constructs distinguish among perceptions of the way managers would like their culture to be (referred to as "should be," i.e., societal cultural values) and the way managers believe things in their culture actually are (referred to as "as is," i.e., societal cultural practice). Using a theory-driven approach, we identified three cultural variables that we believe are related to the ways in which individuals in organizations communicate with one another and as such would have clear links to the relationship between self and others' ratings of leadership. These variables are assertiveness, individualism, and power distance. We did not include GLOBE cultural variables with no clear theoretical links to the relationship between self and other ratings (e.g., future orientation, gender egalitarianism, uncertainty avoidance).

We focused on societal cultural practice variables ("as is") because we believed they reflect the ways values are currently being displayed and are more likely to directly affect how interpersonal interaction and communication take place in each culture (rather than how people "wish" interpersonal interaction and communication were in the culture). We recognized that no measures of culture are without problems, but we believed that we could get a good glimpse of societal differences that may affect organiza- tional behavior by relying on the intensive cross-cultural research of the GLOBE study. While we could not ignore the fact that a single country score may not be representative of each individual's values, we were interested in how societal cultural variables may be related to individuals' communication patterns. The three cultural variables examined in this study and their relevance to self and other ratings are described next.

\section{Assertiveness}

Assertiveness is described as a willingness and interest in expressing positive and negative messages to others. Passive individuals, in contrast to assertive individuals, tend to "fail to express their true thoughts and feelings" (House et al., 2004, p. 397). In many Western cultures considered to be highly assertive, communication is expected to be direct and unambiguous. In less assertive cultures, language is less direct and more subtle (Schneider \& Barsoux, 1997). Highly assertive cultures also value sharing thoughts and feelings while low assertive cultures value remaining detached and private.

"The relationship a leader has with others may also play a role. For instance, an employee voicing disagreement to his or her boss is an accepted and positively evaluated manner of expressing oneself in some cultures but may be unacceptable in others. Whether and how such assertive responding is done and how it is valued depends on societal norms regarding such behavior" (Den Hartog, 2004, p. 399). Because assertiveness is valued among all individuals in high assertiveness cultures regardless of status or role, we expected that direct reports and peers in assertive cultures would more readily and directly share performance feedback with managers on a regular basis. Thus, the manager has more information about his/her direct reports' and peers' reactions to him/ her, and hence, the manager's self-ratings may reflect more of his/her direct reports' and peers' perceptions. This should increase the relationship between the manager's self-ratings and others' ratings.

Therefore, we hypothesized the following:

H1a. The relationship between self and peer ratings of leadership would be positive and higher in cultures that are considered high on assertiveness.

H1b. The relationship between self and subordinate ratings of leadership would be positive and higher in cultures that are considered high on assertiveness.

\section{Individualism/Collectivism}

House et al. (2004) described a number of features of cultures that distinguish between individualism and collectivism. Especially relevant to the relationship between self and others' ratings is the concept of face (a metaphor for one's public self-image). Face-saving or preventing embarrassment is important in Asian cultures and other cultures that are high on collectivism (Kim \& Nam, 1998; Triandis, McCusker, \& Hui, 1990). Moreover, in collectivistic cultures (group-oriented cultures), indirect communication is preferred because the image of group harmony is essential (Fletcher \& Perry, 2001). People in individualistic cultures tend to be more concerned with preserving their own face, whereas people in collectivistic cultures value maintaining the face of the other party. That is, in collectivistic cultures, face giving 
(i.e., allowing room for the other person to maintain or recover his or her face) is important (Ting-Toomey, 1999). Face-saving and face-giving behaviors focus less on the accuracy of a statement and more on what is culturally appropriate for the context (Samovar, Porter, \& McDaniel, 2006). In cultures characterized as collectivistic, face saving and face giving are likely to limit the willingness of people to provide direct negative feedback to others. Because managers in such cultures are therefore likely to receive less direct feedback (as well as less accurate feedback), their self-ratings should be less likely to correspond to ratings from others.

Hall (1976) differentiated cultures on the basis of the type of communication that is emphasized-high or low context. The United States is considered low context, where messages tend to be direct and clear while most Asian cultures, for example, are high context (i.e., more subtle). Gudykunst, Ting-Toomey, and Chua (1988) contended that the "dimensions of low-high-context communication and individualism-collectivism are isomorphic. All cultures Hall (1976) labeled as low context are individualistic and all high-context are collectivistic" (p. 44). These authors went on to assert that high-context cultures are characterized by ambiguous communication while low-context cultures are characterized by direct communication (e.g., "Don't beat around the bush .... Get to the point"). In Japan, a high-context culture, Matsumoto (2004) found that Japanese managers were more likely to provide informal feedback that Americans (in a low-context culture) found frustrating. In sum, individuals in individualistic cultures, in which direct communication is valued, would be more likely to share clear, direct, and easily understood feedback (Aycan \& Kanungo, 2001), and the relationship between self and others' ratings of leadership would therefore be expected to be higher.

Shipper, Hoffman, and Rotondo (2007) studied reactions to $360^{\circ}$ feedback across cultures. They hypothesized and found that in some cultures, feedback is not highly valued or willingly provided. For example, in some Asian cultures, criticism is to be avoided. Additionally, peers in collectivistic cultures may be reluctant to be critical of a group member (whether directly or indirectly) for fear of upsetting the group dynamics and harmony (Hofstede, 2001). Because social interactions in collectivistic cultures often occur in groups, any direct or negative feedback to any particular individual would be discouraged (Aycan \& Kanungo, 2001). Additionally, because individuals may not be comfortable with receiving information that distinguishes them from the collectivity, individual feedback may be avoided and self-awareness will suffer. Sully de Luque and Sommer (2000) proposed that individualistic cultures would provide more individual-focused feedback, whereas collectivist cultures would provide more groupfocused feedback. Again, this would suggest that more information sharing about individual strengths and weaknesses would occur in individualistic cultures.

There is also reason to believe that the self-ratings of managers in individualist cultures may be more likely to agree with their peers' ratings of them. In individualist cultures, an important basis of trust is shared category membership (Yuki, Maddux, Brewer, \& Takemura, 2005). This suggests that because shared category membership exists among peers, trust is likely to be greater among self-raters and their peers in individualist cultures. As a result, information sharing may also be more welcome and truthful. This led us to speculate that self-peer ratings would be more highly positively related in cultures that are higher on individualism.
On the basis of the reasoning that we have reported, we hypothesized the following:

$\mathrm{H} 2 \mathrm{a}$. The relationship between self and peer ratings of leadership would be positive and higher in cultures that are considered high on individualism.

$\mathrm{H} 2 \mathrm{~b}$. The relationship between self and subordinate ratings of leadership would be positive and higher in cultures that are considered high on individualism.

There is also research that suggests that there may be a rating main effect (higher self and other ratings) in individualist cultures. ${ }^{1}$ Specifically, individuals from collectivist cultures have been found to desire negative feedback more than those from individualist cultures, which is consistent with a traditional norm of modesty (Bailey et al., 1997). Having a positive view of oneself and openly expressing it is consistent with the theme of individualism. Previous research has suggested that self-enhancement and leniency biases are more common for self-raters in individualist cultures and less prevalent in collectivist cultures. People in collectivist cultures are more likely to show a modesty bias (Kurman, 2002). Xie, Chen, and Roy (2006) studied respondents from China, Hong Kong, and Taiwan and concluded that those who were more individualistic showed greater leniency in self-rating. We proposed that the modesty bias in collectivist cultures and the leniency biases found in individualist cultures would promote higher selfratings in individualist cultures. However, when it came to rating one's peers or one's boss, it was more difficult to predict whether leniency would prevail in individualist cultures. The emphasis on individual achievement and getting "high scores" could contribute to more lenient ratings. But peer and subordinate ratings might also be more lenient in collectivist cultures due to a reluctance to be critical of others. We believed that because peer and subordinate ratings were anonymous, the tendency not to be critical would be minimized. It is also possible that in collectivist cultures, individuals would be less lenient in ratings of others in an effort not to distinguish one from another. Given the above, we hypothesized the following:

H3a. Self-ratings would be higher in countries that are higher on individualism.

$\mathrm{H} 3 \mathrm{~b}$. Subordinate and peer ratings would be higher in countries that are higher on individualism.

\section{Power Distance}

Power distance as conceptualized by House et al. (2004) reflects the extent to which authority, privileges associated with status, and power differences are accepted by organization or societal members. High power distance cultures readily accept the unequal distribution of power in organizations and show respect and deference to those who hold superior positions. Those in low power distance cultures see few distinctions as a function of position or status and value participation in decisions (Millman, Taylor, \& Czaplewski, 2002). In high power distance cultures, there are more constraints on how individuals at different levels are expected to interact. Researchers have found that individuals from high power

\footnotetext{
${ }^{1}$ We found no prior research that would support hypotheses regarding main effects for assertiveness or power distance. We did test for these main effects, and no significant effects emerged.
} 
distance cultures are reluctant to request information from those below them as it may suggest a lack of knowledge or weakness (Millman et al., 2002). Additionally, because of status differences, if feedback from a subordinate or group of subordinates is perceived as critical or negative, managers from high power distance cultures may be very reluctant to accept it as useful or valid (Fletcher \& Perry, 2001).

Regarding upward feedback, Sully de Luque and Sommer (2000) suggested that equal power distribution "allows workers to move more easily up the organization pyramid ... when engaging in feedback seeking behavior" (p. 842). They proposed that those higher in the status hierarchy are more distanced from those below them in high power distance cultures. Individuals "will not seek information downward because of the importance of maintaining distance" (p. 843). They concluded that feedback seeking in high power distance cultures may be more lateral because there are fewer costs associated with seeking peer feedback than with seeking feedback from superiors or subordinates. Aycan and Kanungo (2001) have also noted that evaluation of superiors by subordinates is difficult to employ in high power distance cultures. "Under the higher power distance style of supervision, there is virtually no rapport between the leader and subordinate" (Carl, Gupta, \& Javidan, 2004, p. 535). Because feedback seeking and the provision of feedback are unlikely to occur across levels in high power distance cultures, we expected more feedback giving and receiving to take place among peers. Leaders should be less reluctant to seek feedback from peers as opposed to bosses or subordinates as they share similar status characteristics. Additionally, in low power distance cultures, there may be more competition among peers and thus a reluctance to share information laterally. Therefore, we hypothesized the following:

H4a. The relationship between self and peer ratings of leadership would be positive and higher in cultures that are considered high on power distance.

H4b. The relationship between self and subordinates' ratings of leadership would be positive and higher in cultures that are considered low on power distance.

\section{Method}

\section{Sample}

Data were collected from 9,819 managers who participated in leadership development programs that used the Benchmarks $360^{\circ}$ feedback instrument (Center for Creative Leadership, 2004). These managers were from 34 different countries. In the current analysis, to achieve sufficient statistical power for the multilevel modeling, following Kreft and DeLeeuw's (1998) suggestions based on simulation studies, we only included data from countries that had at least 10 managers who participated in the study. After this inclusion criterion was implemented, 8,072 managers from 21 countries remained in the dataset. Considering that a majority of the managers in the dataset were from United States $(N=7,264)$, we randomly selected data records of 200 U.S.-based managers to include in the final dataset to make the sample size of U.S.-based managers comparable with those of the rest of countries. The remaining 20 countries had sample sizes that ranged from 10 to 185 managers. The total sample size of the final dataset was 964 managers from 560 different organizations. The average sample size across all 21 countries was $45.90(S D=53.89)$. The median number of organizations represented in each country was 22 (range, 9-200). This distribution ensured that the data for each country was not confounded with only a single organization in that country.

For these 964 managers, ratings of leadership were obtained from 3,576 direct reports and 3,616 peers. The mean age of these managers was $41.04(S D=6.58)$. Approximately $74.1 \%$ of the managers were male; $46.9 \%$ were in upper mid-level management, and $32.1 \%$ were in executive-level management; $87.7 \%$ had at least a bachelor's degree; and $87.3 \%$ were employed by organizations in the private sector. The mean age of these managers' direct reports was $38.44(S D=8.66)$. Approximately $62.6 \%$ of their direct reports were male; $45.5 \%$ were in mid-level management, and $27.3 \%$ were in upper mid-level management; and $73.1 \%$ had at least a bachelor's degree. The mean age of these managers' peer raters was $42.71(S D=7.65)$. Approximately $72.2 \%$ of their peer raters were male; $45.3 \%$ were in upper mid-level management, and $24.9 \%$ were in executive-level management; and $83.7 \%$ had at least a bachelor's degree.

\section{Measures}

Leadership ratings. Benchmarks (Center for Creative Leadership, 2004) is a widely used $360^{\circ}$ feedback instrument that has been extensively researched in the literature (e.g., Atwater, Ostroff, Yammarino, \& Fleenor, 1998; Greguras \& Robie, 1998). It is used primarily for leadership development purposes and captures ratings from managers and their direct reports, peers, and bosses (Lombardo \& McCauley, 1994; Lombardo, McCauley, McDonald-Mann, \& Leslie, 1999). Benchmarks is based on research on how successful managers learn, grow, and change (McCauley \& Lombardo, 1990; Morrison, White, \& Van Velsor, 1987). The instrument has been subjected to a number of validation studies (see Leslie \& Fleenor, 1998) and has received favorable reviews as a valid measure of leadership behavior (Carty, 2003; Spangler, 2003; Zedeck, 1995).

Benchmarks contains 22 scales: 16 scales (in Section 1) deal with managerial skills and perspectives (e.g., leading employees, hiring talented staff, decisiveness, compassion and sensitivity, work team orientation) and 6 scales (in Section 2) deal with potential flaws (e.g., difficulty in making strategic transitions, problems with interpersonal relationships). The self form and the rater form are exactly the same. The instructions say, "Please rate the extent to which this person displays each of the following characteristics. Answer all items as best you can. Use the following scale: 1 = not at all, 2 = to a little extent, 3 = to some extent, $4=$ to a great extent, 5 = to a very great extent."

For the ratings used in the current study, mean intraclass correlations (ICC[2]) were .60 for direct report and .59 for peer ratings, and mean within-group agreement measures, or $r_{\mathrm{wg}(\mathrm{j})}$ values (James, 1988), were .83 for direct report and .85 for peer ratings. These reliabilities were considered high enough to justify aggregating ratings within rater groups in the present study. We therefore aggregated the scores from the 16 scales in Section 1 of Benchmarks to calculate overall peer and direct report ratings of leadership.

Cultural practices. The measures of individualism/collectivism, assertiveness, and power distance were taken from the 
GLOBE data collected and complied on 62 countries. The ways in which these scores were created are described in detail in House et al. (2004). They reported the alpha coefficients as .75 for assertiveness, .67 for individualism, and .80 for power distance. The cultural attributes measured here were referred to as the way things are or "as is." Each item was measured on a 1-7 scale. The anchors were relevant to each construct. In a sample item measuring assertiveness, participants were asked how assertive people in their society were (scale ranging from 1 , assertive, to 7 , nonassertive; reverse scored); in a sample item measuring individualism, participants were asked whether leaders encouraged group loyalty even if individual goals suffered (from 1, strongly agree, to 7, strongly disagree); in a sample item measuring power distance, participants were asked the degree to which their society expected followers to obey their leader (from 1, without question, to 7, question leaders when in disagreement; reverse scored). The means obtained from managers in each country were averaged to create the country scores. Table 1 lists the 21 countries included in this study and the scores for each of the countries on assertiveness, individualism, and power distance, as well as the means and standard deviations for self, peer, and subordinate ratings of leadership.

\section{Analytic Strategy}

Using Mplus 4.0 (Muthén \& Muthén, 2006), we tested our hypotheses via multilevel modeling. This is because each manager in our sample was nested under the corresponding country culture from which he or she came. Using multilevel modeling to analyze nested data is superior to using ordinary least square (OLS) regression because including individuals from the same groups (e.g., countries) violates regression assumptions and can underestimate or overestimate standard errors for parameter estimates, leading to the overestimation or underestimation of relationships (Bryk \& Raudenbush, 1992; Snijders \& Bosker, 1999). In the current study, to test the main effects of cultural context variables on leadership ratings from each rating source, we estimated an intercept-only regression model for leadership ratings at Level 1 and predictive effects of cultural variables on the Level-1 random intercept were estimated at Level 2. To test the cross-level moderating effects of cultural variables, we treated the Level-1 random regression slopes of peer and subordinate ratings in predicting self ratings as dependent variables of Level-2 cultural practice variables. Following Hofmann and Gavin's (1998) suggestion, to avoid interpretation difficulties and spurious findings, we centered both peer ratings and subordinate ratings by group means when entering them into corresponding multilevel models. In addition, to provide a realistic view of how these cultural practices operate in concert with each, we included them together simultaneously as Level-2 predictors in the analysis.

\section{Results}

Means, standard deviations, and correlations among all variables across countries are presented in Table 2. In particular, the correlations between self ratings and others' ratings of leadership were modest in size $(r \mathrm{~s}=.14, p \mathrm{~s}<.01)$.

\section{Testing Main Effects of Cultural Context Variables}

To test main effects of cultural context variables in predicting leadership ratings from each rating source, we focused on examining their predictive coefficients (i.e., $\gamma_{01}, \gamma_{02}$, and $\gamma_{03}$ ) for the random intercept $\left(\beta_{0}\right)$. Specifically, as reported in Table 3, only the main effects of individualism were significantly and positively

Table 1

Cultural Practice Scores and Leadership Ratings for the 21 Countries Included in the Study

\begin{tabular}{|c|c|c|c|c|c|c|c|c|c|}
\hline \multirow[b]{3}{*}{ Country } & \multirow{3}{*}{$\begin{array}{c}\text { Assertiveness } \\
\text { mean }\end{array}$} & \multirow{3}{*}{$\begin{array}{c}\text { Individualism } \\
\text { mean }\end{array}$} & \multirow{3}{*}{$\begin{array}{c}\text { Power } \\
\text { distance } \\
\text { mean }\end{array}$} & \multicolumn{6}{|c|}{ Leadership rating } \\
\hline & & & & \multicolumn{2}{|c|}{ Self } & \multicolumn{2}{|c|}{ Peer } & \multicolumn{2}{|c|}{ Subordinate } \\
\hline & & & & $M$ & $S D$ & $M$ & $S D$ & $M$ & $S D$ \\
\hline Austria & 4.62 & 3.70 & 4.95 & 3.85 & 0.40 & 3.75 & 0.39 & 4.09 & 0.29 \\
\hline Brazil & 4.20 & 4.17 & 5.33 & 4.00 & 0.28 & 3.91 & 0.29 & 3.88 & 0.37 \\
\hline Canada & 4.05 & 3.62 & 4.82 & 3.80 & 0.34 & 3.81 & 0.35 & 4.03 & 0.34 \\
\hline China & 3.76 & 3.23 & 5.04 & 3.85 & 0.36 & 3.69 & 0.35 & 3.79 & 0.40 \\
\hline Denmark & 3.80 & 3.20 & 3.89 & 3.84 & 0.28 & 3.74 & 0.21 & 3.92 & 0.32 \\
\hline Finland & 3.81 & 3.37 & 4.89 & 3.86 & 0.30 & 3.81 & 0.34 & 3.82 & 0.21 \\
\hline France & 4.13 & 4.07 & 5.28 & 3.89 & 0.29 & 3.93 & 0.27 & 3.89 & 0.38 \\
\hline Hong Kong & 4.67 & 3.87 & 4.96 & 4.04 & 0.32 & 3.90 & 0.32 & 3.71 & 0.36 \\
\hline India & 3.73 & 3.62 & 5.47 & 4.00 & 0.34 & 3.95 & 0.41 & 3.96 & 0.49 \\
\hline Ireland & 3.92 & 3.37 & 5.15 & 3.73 & 0.32 & 3.71 & 0.35 & 3.80 & 0.42 \\
\hline Italy & 4.07 & 4.32 & 5.43 & 3.95 & 0.32 & 3.80 & 0.41 & 3.92 & 0.36 \\
\hline Mexico & 4.45 & 3.94 & 5.22 & 3.89 & 0.36 & 3.98 & 0.29 & 3.94 & 0.44 \\
\hline Netherlands & 4.32 & 3.54 & 4.11 & 3.78 & 0.29 & 3.70 & 0.32 & 3.63 & 0.30 \\
\hline Poland & 4.06 & 3.47 & 5.10 & 3.59 & 0.30 & 3.69 & 0.37 & 3.90 & 0.34 \\
\hline Russia & 3.68 & 3.50 & 5.52 & 3.78 & 0.27 & 3.80 & 0.29 & 4.04 & 0.30 \\
\hline South Korea & 4.40 & 2.80 & 5.61 & 3.70 & 0.36 & 3.67 & 0.42 & 3.84 & 0.28 \\
\hline Singapore & 4.17 & 3.10 & 4.99 & 3.93 & 0.39 & 3.80 & 0.35 & 3.83 & 0.63 \\
\hline Spain & 4.42 & 4.15 & 5.52 & 3.87 & 0.23 & 3.85 & 0.28 & 4.01 & 0.23 \\
\hline Sweden & 3.38 & 2.78 & 4.85 & 3.88 & 0.29 & 3.91 & 0.29 & 3.78 & 0.28 \\
\hline United Kingdom & 4.15 & 3.73 & 5.15 & 3.81 & 0.31 & 3.79 & 0.36 & 3.84 & 0.38 \\
\hline United States & 4.55 & 3.80 & 4.88 & 3.87 & 0.36 & 3.93 & 0.41 & 4.00 & 0.45 \\
\hline
\end{tabular}


Table 2

Means, Standard Deviations, and Correlations Among Variables

\begin{tabular}{lcccccccc}
\hline & & & \multicolumn{5}{c}{ Correlation } \\
\cline { 5 - 9 } \multicolumn{1}{c}{ Variable } & $M$ & $S D$ & 1 & 2 & 3 & 4 & 5 & 6 \\
\hline 1. Assertiveness & 4.11 & 0.34 & - & & & & \\
2. Individualism & 3.59 & 0.43 & $.46^{*}$ & - & & & \\
3. Power distance & 5.05 & 0.43 & .07 & .29 & - & & \\
4. Peer ratings of leadership & 3.83 & 0.37 & $.07^{* *}$ & $.12^{* *}$ & $.09^{* * *}$ & - & \\
5. Subordinate ratings of leadership & 3.89 & 0.41 & $.08^{* *}$ & $.10^{* *}$ & $.09^{* * *}$ & $.35^{* *}$ & - \\
6. Self-ratings of leadership & 3.84 & 0.33 & .01 & $.08^{* *}$ & .06 & $.14^{* *}$ & $.14^{* * *}$ & - \\
\hline
\end{tabular}

Note. $\quad N=964$ for the correlations between individual-level variables (Variables 4-6) and country-level variables (Variables 1-3), because to calculate them, we assigned the same country-level scores to all individuals who were from the same country. The correlations between two country-level variables were calculated at the country level with a sample size of $N=21$.

${ }^{*} p<.05 .{ }^{* *} p<=.01$.

related to leadership ratings from all three rating sources (for self ratings, $\gamma_{02}=0.107, z=2.18, p<.05$; for peer ratings, $\gamma_{02}=$ $0.102, z=1.85, p<.10$; for subordinate ratings, $\gamma_{02}=0.107, z=$ $2.06, p<.05)$. These findings suggest that in support of H3a and $\mathrm{H} 3 \mathrm{~b}$, leaders are more likely to give themselves higher ratings and to receive higher ratings from their peers and subordinates in cultures that are higher on individualism.

Further, comparing the residual variances of the current models with nested models that did not contain the Level-2 cultural variables (i.e., the random intercept model without Level-2 predictors in Table 3), we found that cultural practice variables explained $16.7 \%$ of the variance in the random intercept for self ratings, $12.5 \%$ of the variance in the random intercept for peer ratings, and $11.8 \%$ of the variance in the random intercept of subordinate ratings. Nevertheless, the residual variances in random intercepts were all significant, suggesting that other country-level predictors may be added to fully account for the variation in these random intercepts.

\section{Testing Cross-Level Moderation Effects of Cultural Context Variables}

To test the cross-level moderation hypotheses, we estimated two multilevel models that examined how cultural context variables predict the relationships between peer/subordinate ratings and self ratings of leadership. Specifically, we entered peer ratings and subordinate ratings, respectively, as the Level-1 predictor of self ratings of leadership in the two models. We then entered three

Table 3

Multilevel Models for Testing Main Effects of Cultural Practices on Leadership Ratings

\begin{tabular}{|c|c|c|c|c|c|c|}
\hline \multirow[b]{3}{*}{ Model } & \multicolumn{6}{|c|}{ Dependent variable } \\
\hline & \multicolumn{2}{|c|}{ Self-rating } & \multicolumn{2}{|c|}{ Peer rating } & \multicolumn{2}{|c|}{ Subordinate rating } \\
\hline & Coefficient & $S E$ & Coefficient & $S E$ & Coefficient & $S E$ \\
\hline & \multicolumn{6}{|c|}{ Random intercept model without Level-2 predictors } \\
\hline Level 1-variance $\left(\sigma_{\text {within }}^{2}\right)$ & $0.109^{* *}$ & 0.007 & $0.129^{* *}$ & 0.010 & $0.155^{* *}$ & 0.016 \\
\hline \multicolumn{7}{|l|}{ Level 2-random intercept $\left(\beta_{0}\right)$} \\
\hline Intercept $\left(\gamma_{00}\right)$ & $3.852^{* *}$ & 0.019 & $3.819^{* *}$ & 0.022 & $3.883^{* *}$ & 0.026 \\
\hline \multirow[t]{2}{*}{ Variance $\left(\tau_{0}\right)$} & $0.012^{* * *}$ & 0.004 & $0.016^{* *}$ & 0.004 & $0.017^{*}$ & 0.008 \\
\hline & \multicolumn{6}{|c|}{ Random intercept model with Level-2 predictors } \\
\hline Level 1 -variance $\left(\sigma_{\text {within }}^{2}\right)$ & $0.109^{* * *}$ & 0.007 & $0.128^{* *}$ & 0.010 & $0.155^{* *}$ & 0.016 \\
\hline \multicolumn{7}{|l|}{ Level 2-random intercept $\left(\beta_{0}\right)$} \\
\hline Intercept $\left(\gamma_{00}\right)$ & $3.611^{* * *}$ & 0.219 & $3.311^{* *}$ & 0.372 & $3.250^{* * *}$ & 0.466 \\
\hline Assertiveness $\left(\gamma_{01}\right)$ & -0.056 & 0.058 & -0.022 & 0.082 & 0.002 & 0.085 \\
\hline Individualism $\left(\gamma_{02}\right)$ & $0.107^{*}$ & 0.049 & $0.102^{\dagger}$ & 0.055 & $0.068^{*}$ & 0.033 \\
\hline Power distance $\left(\gamma_{03}\right)$ & 0.017 & 0.032 & 0.046 & 0.038 & 0.076 & 0.084 \\
\hline Residual variance $\left(\sigma_{\mathrm{e} 0}^{2}\right)$ & $0.010^{* * *}$ & 0.003 & $0.014^{* *}$ & 0.005 & $0.015^{*}$ & 0.007 \\
\hline \multicolumn{7}{|l|}{$\begin{array}{l}\text { Variance in random intercept } \\
\text { accounted for by Level-2 }\end{array}$} \\
\hline predictors $(\%)$ & 16.7 & & 12.5 & & 11.8 & \\
\hline
\end{tabular}

Note. Level-1 $N=964 ;$ Level- $2 N=21$

${ }^{*} p<=.05$. ${ }^{* *} p<=.01{ }^{\dagger} p<.10$. 
cultural variables as the Level-2 predictors in predicting the random intercept $\left(\beta_{0}\right)$ and random slope $\left(\beta_{1}\right)$ from the Level-1 regression. The coefficients of cultural practice variables (i.e., $\gamma_{11}$, $\gamma_{12}$, and $\gamma_{13}$ ) provided the test of our hypotheses. As indicated in Table 4, assertiveness was significantly related to the peer ratingself-rating slope, $\gamma_{11}=0.085, z=2.74, p<.01$. We plotted the significant interaction at conditional values of cultural assertiveness (i.e., $\pm S D$ ) following Cohen, Cohen, West, and Aiken's (2003) procedure. As shown in Figure 1, the relationship between self and peer ratings is stronger in cultures that are higher on assertiveness, supporting H1a. A similar finding was obtained for the subordinate rating-self-rating slope: assertiveness was positively and significantly related to the subordinate rating-self-rating slope, $\gamma_{11}=0.184, z=2.16, p<.05$. As shown in Figure 2, the relationship between self and subordinate ratings is stronger in cultures that are higher on assertiveness, supporting H1b. We also found that power distance was significantly and positively related

Table 4

Multilevel Models for Testing Cross-Level Moderation Effects of Cultural Practices

\begin{tabular}{|c|c|c|c|c|}
\hline \multirow[b]{3}{*}{ Model } & \multicolumn{4}{|c|}{ Level-1 prediction } \\
\hline & \multicolumn{2}{|c|}{$\begin{array}{l}\text { Peer ratings } \rightarrow \text { self- } \\
\text { ratings }\end{array}$} & \multicolumn{2}{|c|}{$\begin{array}{l}\text { Subordinate } \\
\text { ratings } \rightarrow \text { self- } \\
\text { ratings }\end{array}$} \\
\hline & Coefficient & $S E$ & Coefficient & $S E$ \\
\hline & \multicolumn{4}{|c|}{$\begin{array}{l}\text { Random intercept and slope model } \\
\text { without Level-2 predictors }\end{array}$} \\
\hline \multicolumn{5}{|l|}{ Level 2} \\
\hline \multicolumn{5}{|l|}{ Random intercept $\left(\beta_{0}\right)$} \\
\hline Intercept $\left(\gamma_{00}\right)$ & $3.852^{* *}$ & 0.019 & $3.852^{* *}$ & 0.019 \\
\hline Variance $\left(\tau_{0}\right)$ & $0.012^{* * *}$ & 0.004 & $0.012^{* *}$ & 0.004 \\
\hline \multicolumn{5}{|l|}{ Random slope $\left(\beta_{1}\right)$} \\
\hline Intercept $\left(\gamma_{10}\right)$ & $0.078^{*}$ & 0.032 & $0.094^{*}$ & 0.047 \\
\hline \multirow[t]{2}{*}{ Variance $\left(\tau_{1}\right)$} & $0.008^{*}$ & 0.004 & $0.009^{* *}$ & 0.003 \\
\hline & \multicolumn{4}{|c|}{$\begin{array}{l}\text { Random intercept and slope model with } \\
\text { Level-2 predictors }\end{array}$} \\
\hline Level 1-variance $\left(\sigma_{\text {within }}^{2}\right)$ & $0.107^{* *}$ & 0.007 & $0.107^{* *}$ & 0.007 \\
\hline Level 2 & & & & \\
\hline & & & & \\
\hline Intercept $\left(\gamma_{00}\right)$ & $3.612^{\text {*** }}$ & 0.218 & $3.612^{* * *}$ & 0.218 \\
\hline Assertiveness $\left(\gamma_{01}\right)$ & -0.056 & 0.058 & -0.056 & 0.058 \\
\hline Individualism $\left(\gamma_{02}\right)$ & $0.107^{*}$ & 0.049 & $0.107^{*}$ & 0.049 \\
\hline Power distance $\left(\gamma_{03}\right)$ & 0.016 & 0.032 & 0.016 & 0.032 \\
\hline Residual variance $\left(\sigma_{\mathrm{e} 0}^{2}\right)$ & $0.010^{* * *}$ & 0.003 & $0.010^{* *}$ & 0.003 \\
\hline \multicolumn{5}{|l|}{ Random slope $\left(\beta_{1}\right)$} \\
\hline Intercept $\left(\gamma_{10}\right)$ & -0.683 & 1.474 & -1.301 & 0.924 \\
\hline Assertiveness $\left(\gamma_{11}\right)$ & $0.085^{* * *}$ & 0.031 & $0.184^{*}$ & 0.085 \\
\hline Individualism $\left(\gamma_{12}\right)$ & -0.049 & 0.189 & -0.002 & 0.088 \\
\hline Power distance $\left(\gamma_{13}\right)$ & $0.119^{*}$ & 0.052 & $0.125^{*}$ & 0.060 \\
\hline Residual variance $\left(\sigma_{\mathrm{e} 0}^{2}\right)$ & 0.004 & 0.016 & 0.002 & 0.003 \\
\hline $\begin{array}{l}\text { Variance in random } \\
\text { intercept accounted for } \\
\text { by Level-2 predictors } \\
(\%)\end{array}$ & 50.0 & & 77.8 & \\
\hline
\end{tabular}

Note. Level-1 $N=964$; Level-2 $N=21$. Predictors at Level 1 were centered by group means.

${ }^{*} p<=.05$. * $p<=.01$.

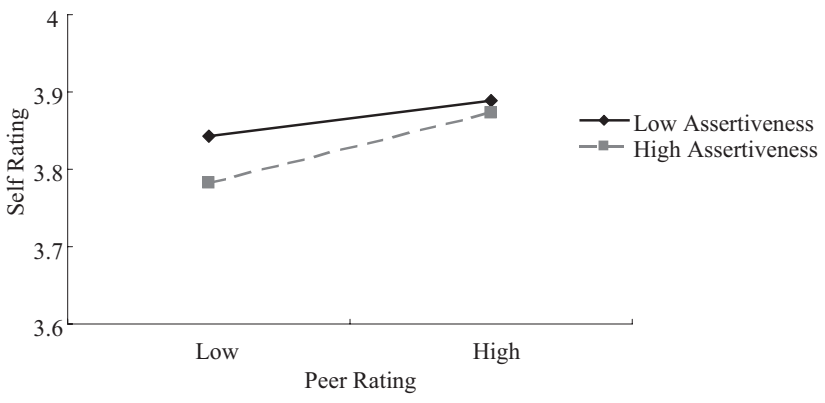

Figure 1. Assertiveness as a moderator of the peer rating-self-rating relationship.

to the peer rating-self-rating slope, $\gamma_{13}=0.119, z=2.29, p<.05$. As plotted in Figure 3 , the relationship between self and peer ratings is stronger in cultures that have higher power distance, supporting H4a. Power distance was also significantly related to the subordinate rating-self-rating slope but in the direction opposite to $\mathrm{H} 4 \mathrm{~b}, \gamma_{13}=0.125, z=2.08, p<.05$. This indicates that the relationship between self and subordinate ratings is stronger in cultures that have higher power distance (see Figure 4). Individualism did not show positive effects in predicting either the peer rating-self-rating slope or the subordinate rating-self-rating slope, providing no support for $\mathrm{H} 2 \mathrm{a}$ or $\mathrm{H} 2 \mathrm{~b}$.

Further, comparing the residual variances of the current models with nested models that did not contain the cross-level interaction term of cultural variables (i.e., the random intercept and slope model without Level-2 predictors in Table 4), we found that as a set of predictors, cultural variables explained $50.0 \%$ of the variance in the random peer rating-self-rating slope and $77.8 \%$ of the variance in the random subordinate rating-self-rating slope. Overall, these findings suggest that cultural variables are related to the relationships between self and other ratings.

\section{Discussion}

We used a theory-driven approach to assess the way in which cultural context variables might affect (moderate) the relationship between self and others' ratings of leadership. Consistent with our first two hypotheses, we found that the relationship between self and peer ratings of leadership, and the relationship between self and subordinate ratings of leadership, were higher in countries that

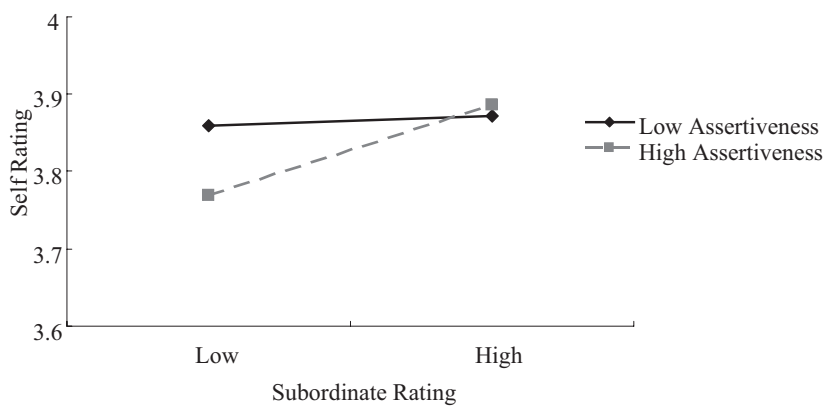

Figure 2. Assertiveness as a moderator of the subordinate rating-selfrating relationship. 


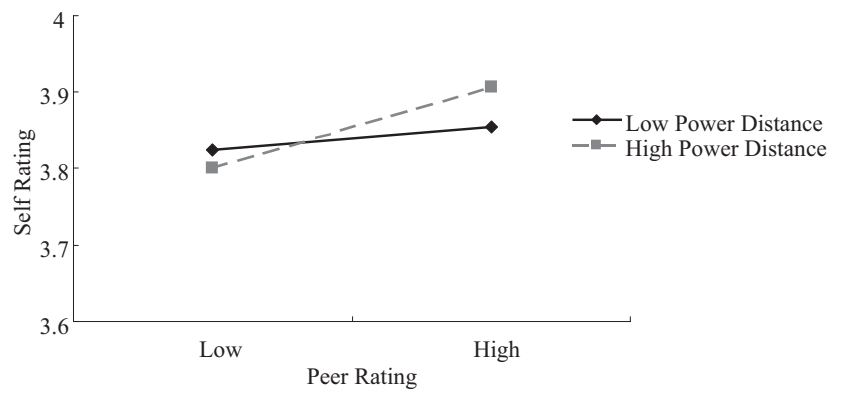

Figure 3. Power distance as a moderator of the peer rating-self-rating relationship.

are characterized by high assertiveness. This makes sense because assertive cultures are characterized by people directly expressing their true thoughts and feelings regardless of their status or power relationships. In such cultures, managers are more likely to know how others (both peers and subordinates) evaluate their leadership skills, and this, in turn, can affect managers' self-evaluations.

Our second two hypotheses were not supported. We found that the relationships between self and subordinate/peer ratings of leadership were not more strongly positive in countries characterized by high individualism after we controlled for assertiveness and power distance. This was somewhat surprising and likely driven by the relationship between assertiveness and individualism. Consistent with our third set of hypotheses, we found a main effect for individualism on self-ratings, suggesting a leniency bias in individualist cultures, or a modesty bias in collectivist cultures, or both. Peer and subordinate ratings were also higher in individualist cultures, suggesting that they too tended to be more lenient in their ratings.

Hypothesis 4a was supported. The relationship between self and peer ratings of leadership was higher in countries characterized by high power distance. We attribute this to the notion that lateral communication will be more candid than upward or downward communication in high power distance cultures. But contrary to our Hypothesis $4 \mathrm{~b}$, the relationship between self and subordinate ratings of leadership was also higher (rather than lower) in countries characterized by high power distance. One possible explanation for this unexpected finding is that high power distance cultures tend to be characterized by clear role expectations such that leaders and subordinates know what is expected of them and of each other. This, in turn, might lead to higher congruence between self-ratings and subordinates' ratings of leadership.

The average number of leaders per country in the current study was 46 . Such a small number of leaders per country would be a limitation if we had studied only a very small number of countries (e.g., contrasting about 50 managers from one country that is high on assertiveness with about 50 managers from another country that is low on assertiveness). However, unlike a number of other studies, we did not treat only one country as an exemplar of a cultural characteristic (e.g., low assertiveness). To do so would have required having a reasonably large and representative sample from that country to ensure that the sample mean and variance were representative of the country's mean and variance on that cultural characteristic. In contrast, in the current study, each cultural characteristic was in essence represented by several countries (e.g., all those countries that are relatively low on assertiveness). We did not examine whether the slope (between self and others' ratings of leadership) is different in Country $\mathrm{X}$ versus Country $\mathrm{Y}$ but instead whether the slope is different in countries that are high on a cultural characteristic versus countries that are low on that cultural characteristic. Given that we were able to combine data of 964 leaders from 21 countries, we in essence compared hundreds of leaders from relatively high assertiveness countries with hundreds of leaders from relatively low assertiveness countries. In sum, one strength of the current study is its ability to enable inferences about whether assertiveness, individualism, and power distance moderate the relationship between self and others' ratings on the basis of hundreds of managers from many countries.

\section{Implications and Suggestions for Future Research}

Our finding that the relationship between self and others' ratings of leadership is stronger in countries with some cultural characteristics than others raises the question of whether self-awareness (e.g., a high correlation between self and others' ratings of leadership) is an equally important predictor of managerial effectiveness across cultures. In the United States, a lack of self-awareness has been shown to be related to lower performance (cf. Atwater, Roush, \& Fischthal, 1995; Church, 1997) and to career derailment (McCall \& Lombardo, 1983), but in cultures in which direct communication is less valued and face saving is more important, self-awareness may not be as relevant to career success.

Atwater, Waldman, Ostroff, Robie, and Johnson (2005) recently found that the correspondence between self and others' (subordinate and peer) ratings of leadership was less useful in predicting managerial effectiveness in five European countries (United Kingdom, Germany, France, Denmark, and Italy) than in the United States. In the United States, the correspondence between self and others' ratings of leadership predicted managerial effectiveness, whereas in the European countries, only others' ratings of leadership predicted managerial effectiveness.

It would be helpful to understand whether the relationship between (a) the correspondence between self and others' ratings of leadership skills and (b) management effectiveness varies as a function of cultural characteristics. For example, it is possible that the correspondence between self and others' ratings of leadership matters less in predicting effectiveness in cultures with various cultural characteristics (e.g., those that are characterized by low

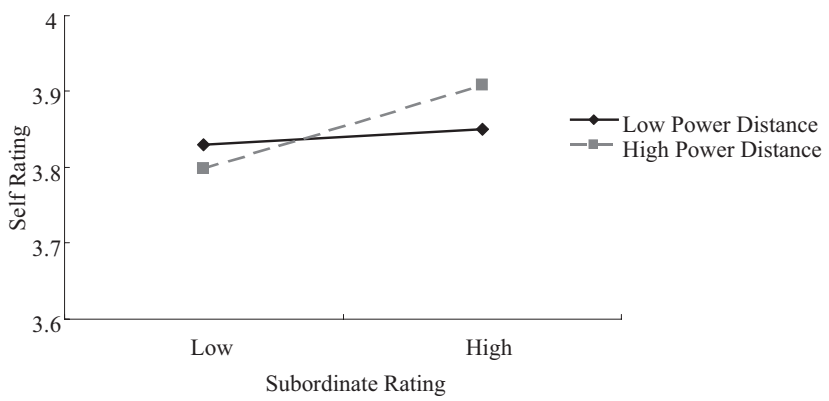

Figure 4. Power distance as a moderator of the subordinate rating-selfrating relationship. 
assertiveness and high collectivism) than it does in the United States.

Investigations that directly measure the frequency and nature of performance feedback in different cultures would be especially valuable. For example, it would be helpful to know whether subordinates and peers in low assertiveness and high collectivist cultures actually provide less feedback, especially negative feedback, to managers. Anecdotal information from face-to-face interactions with Korean executive MBAs suggests that subordinates do not feel compelled to answer $360^{\circ}$ feedback questions honestly (M. S. DeLuque, personal communication, January 7, 2008). This reluctance may contribute to lower self-other congruence in more collectivist cultures.

Recent reviews of the cross-cultural literature (Gelfand et al., 2007; Kirkman, Lowe, \& Gibson, 2006; Tsui, Nifadkar, \& Ou, 2007) have pointed out that cultural variables such as individualism, assertiveness, and power distance are also meaningful at the organizational and individual levels of analysis. This raises the question of whether the current findings would also be observed if cultural variables had been measured at the organizational or individual level of analysis. We expect that similar findings would be observed at the organizational level of analysis. The items as measured by GLOBE are the same at the country and organizational levels (e.g., "People in this country are generally assertive" versus "People in this organization are generally assertive"). Also, according to Brodbeck, Hanges, Dickson, Gupta, and Dorfman (2004), societal values had a significant effect on all nine organizational cultural practice dimensions, accounting for between $21 \%$ and $47 \%$ of the variance. They concluded that "societal-level differences have a substantial impact on the cultural practices in organizations" (p. 659). At the individual level of analysis, the picture could become more complicated. If both the leader and the follower are similar (e.g., both high on assertiveness or both low on assertiveness), then we expect similar findings would be observed at the individual level. For example, if both the leader and the follower are assertive, candid communication between the two parties would likely increase the correspondence between the leader's self-ratings and the follower's ratings of the leader. But the picture could become more complicated if the leader and the follower differ (e.g., the leader is high on assertiveness, but the follower is low on assertiveness). Such differences might detract from candid communication between the two parties and hence reduce the correspondence between the leader's self-ratings and the follower's ratings of the leader. These questions are worthy of future research.

The current study used "as is" scores from GLOBE. These "as is" scores capture current practices and behavior in each culture. Indeed, the logic underlying our hypotheses was based on how culture shapes current practices and behavior in organizations ("as is"). That is, we were interested in contrasting cultures in which communication and feedback tend to be direct, blunt, and candid with cultures in which communication and feedback tend to be cautious and indirect. Our hypotheses were based on the culture as it is now, not how people think it ought to be. Therefore, it was essential that we used GLOBE "as is" scores, not "should be" scores. However, there are circumstances in which it would make conceptual sense to examine GLOBE "should be" scores. For example, investigators who examine how culture shapes acceptance of organizational change initiatives might hypothesize that acceptance of change would be higher if the change initiative corresponds (or is congruent) with how participants think the culture "should be." One issue in the use of "as is" and "should be" scores from GLOBE is the negative correlation typically observed between such scores (House et al., 2004). That is, managers typically appear to think that their culture should be different than it is such that managers from cultures characterized by high assertiveness ("as is") would like the culture to be somewhat less assertive ("should be") and vice versa. This phenomenon of a negative correlation between "as is" and "should be" scores is observed with seven of nine of the GLOBE dimensions and raises methodological questions about the use and interpretation of "should be" scores.

Future research could also examine the possibility of meaningful configural relationships among cultural characteristics (i.e., patterns of cultural characteristics). Such an analysis would focus on patterns of scores as predictors (e.g., comparing countries that are high on Cultural Characteristics A and B but low on Cultural Characteristic $\mathrm{C}$ with countries that are high on $\mathrm{A}$ and $\mathrm{C}$ but low on B). Of course, such research would require large and very heterogeneous samples of countries.

\section{Limitations}

The results of this study should be considered in light of its limitations. Due to limited sample sizes in some countries, we were able to examine only 21 of the 34 countries that were in our larger data set. Also, it would be helpful for future research to determine whether the results we observed could be replicated with a different sample of countries.

Also, as noted above, the number of managers in some of our countries was quite small. When this occurs, the estimate of the slope in that country (e.g., between self and subordinate ratings) has a large standard error. This, in turn, can affect the ability of Level-2 analyses to determine the strength of the relationship between cultural characteristics and Level-1 slopes. Thus, it would naturally be desirable to replicate the current study with larger samples sizes, both for Level-1 analyses (the number of managers within each country) and for Level-2 analyses (the number of countries).

The current study examined whether cultural characteristics are related to the relationship (slope) between self and others' ratings, but there are likely to be circumstances in which researchers will be interested in the agreement (difference) between self and other's ratings. Future research could examine whether cultural characteristics are related to the agreement (difference) between self and others' ratings. Although Edwards (1995) has described how to handle difference scores as outcome measures in multiple regression, we know of no research that has examined agreement as an outcome (dependent) variable using a multilevel modeling framework (where Level-2 scores are used to predict the Level-1 agreement between self and others' ratings). The procedures described by Edwards (1995) currently cannot control for the nesting nature of multilevel data such as that analyzed here. Given that testing the effect of cultural practices was the main focus of the current study, it was important for us to attend to the nesting nature of the data and derive the unbiased standard error estimates to accurately evaluate this effect, and this is why we selected multilevel modeling to analyze the current data. 
It is also the case that we did not attempt to measure the mechanisms underlying our effects. For example, while we speculated that communication style may underlie some effects, to truly capture these mechanisms requires further study.

In sum, this is the first study to show that the relationship between self and others' ratings of leadership skills is moderated by cultural characteristics. We hope it serves as an important first step for further cross-cultural investigations concerning selfawareness and its relationship to managerial effectiveness.

\section{References}

Ashford, S. (1989). Self-assessments in organizations: A literature review and integrative model. Research in Organizational Behavior, 11, 133174.

Atwater, L., Ostroff, C., Yammarino, F., \& Fleenor, J. (1998). Self-other agreement: Does it matter? Personnel Psychology, 51, 577-598.

Atwater, L., Roush, P., \& Fischthal, A. (1995). The influence of upward feedback on self and other ratings of leadership. Personnel Psychology, $48,35-59$.

Atwater, L., Waldman, D., Ostroff, C., Robie, C., \& Johnson, K. M. (2005). Self-other agreement: Comparing its relationship with performance in the U.S. and Europe. International Journal of Selection and Assessment, 13, 25-40.

Aycan, Z., \& Kanungo, R. N. (2001). Cross-cultural industrial and organizational psychology: A critical appraisal of the field and future directions. In N. Anderson, D. Ones, H. K. Sinangil, \& C. Viswesvaran (Eds.), Handbook of industrial, work, and organizational psychology: Volume 1. Personnel psychology. Thousand Oaks, CA: Sage.

Bailey, J., Chen, C., \& Dou, S. (1997). Conceptions of self and performance-related feedback in the U. S., Japan, and China. Journal of International Business Studies, 28, 605-625.

Brodbeck, F., Hanges, P., Dickson, M., Gupta, V., \& Dorfman, P. (2004). Societal culture and industrial sector influences on organizational culture. In R. House, P. Hanges, M. Javidan, P. Dorfman, \& V. Gupta (Eds.), Culture, leadership and organizations (pp. 654-668.). Thousand Oaks, CA: Sage.

Brutus, S., Fleenor, J., \& McCauley, C. (1999). Demographic and personality predictors of congruence in multi-source ratings. Journal of Management Development, 18, 417-435.

Bryk, A. S., \& Raudenbush, S. W. (1992). Hierarchical linear models: Applications and data analysis methods. Newbury Park, CA: Sage.

Carl, D., Gupta, V., \& Javidan, M. (2004). Power distance. In R. House, P. Hanges, M. Javidan, P. Dorfman, \& V. Gupta (Eds.), Culture, leadership, and organizations (pp. 395-436). Thousand Oaks, CA: Sage.

Carty, H. M. (2003). Review of Benchmarks [revised]. In B. S. Plake, J. Impara, \& R. A. Spies (Eds.), The fifteenth mental measurements yearbook (pp. 123-124). Lincoln, NE: Buros Institute of Mental Measurements.

Center for Creative Leadership. (2004). Benchmarks facilitators' manual. Greensboro, NC: Author.

Church, A. (1997). Managerial self-awareness in high-performing individuals in organizations. Journal of Applied Psychology, 82, 281-292.

Cohen, J., Cohen, P., West, S., \& Aiken, L. (2003). Applied multiple regression/correlation analysis for the behavioral sciences (3rd ed.). Hillsdale, NJ: Erlbaum.

Den Hartog, D. (2004). Assertiveness. In R. House, P. Hanges, M. Javidan, P. Dorfman, \& V. Gupta (Eds.), Culture, leadership, and organizations (pp. 395-436). Thousand Oaks, CA: Sage.

Edwards, J. R. (1995). Alternatives to difference scores as dependent variables in the study of congruence in organizational research. Organizational Behavior and Human Decision Processes, 64, 307-324.

Fletcher, C., \& Perry, E. L. (2001). Performance appraisal and feedback: A consideration of national culture and a review of contemporary research and future trends. In N. Anderson, D. Ones, H. K. Sinangil, \& C. Viswesvaran (Eds.), Handbook of industrial, work, and organizational psychology: Volume 1. Personnel psychology. Thousand Oaks, CA: Sage.

Gelfand, M. J., Erez, M., \& Aycan, Z. (2007). Cross-cultural organizational behavior. Annual Review of Psychology, 58, 479-514.

Greguras, G. J., \& Robie, C. (1998). A new look at within-source interrater reliability of 360-degree feedback ratings. Journal of Applied Psychology, 83, 960-968.

Gudykunst, W., Ting-Toomey, S., \& Chua, E. (1988). Culture and interpersonal communication. Newbury Park: Sage.

Hall, E. T. (1976). Beyond culture. New York: Doubleday.

Harris, M., \& Schaubroeck, J. (1988). A meta-analysis of self-supervisor, self-peer, and peer-supervisor ratings. Personnel Psychology, 41, 43-61.

Hofmann, D., \& Gavin, M. (1998). Centering decisions in hierarchical linear models: Implications for research in organizations. Journal of Management, 24, 623-641.

Hofstede, G. (2001). Culture's consequences: Comparing values, behaviors, institutions and organizations across nations (2nd ed., Rev.). Thousand Oaks, CA: Sage.

House, R., Hanges, P., Javidan, M., Dorfman, P., \& Gupta, V. (2004). Culture, leadership, and organizations. Thousand Oaks, CA: Sage.

James, L. R. (1988). Organizational climate: Another look at a potentially important construct. In S. G. Cole \& R. G. Demaree (Eds.), Applications of interactionist psychology: Essays in honor of Saul B. Sells (pp. 253-282). Hillsdale, NJ: Lawrence Erlbaum.

Kim, J. Y., \& Nam, S. H. (1998). The concept and dynamics of face: Implications for organizational behavior in Asia. Organization Science, 9, 522-534

Kirkman, B., Lowe, K., \& Gibson, C. (2006). A quarter century of Culture's Consequences: A review of empirical research incorporating Hofstede's cultural values framework. Journal of International Business Studies, 37, 285-320.

Kreft, I., \& DeLeeuw, J. (1998). Introducing multilevel modeling. New York: Sage.

Kruger, J., \& Dunning, D. (1989). Unskilled and unaware of it: How difficulties in recognizing one's own incompetence lead to inflated self-assessments. Journal of Personality and Social Psychology, 77, $1121-1134$

Kurman, J. (2002). Measured cross-cultural differences in self enhancement and the sensitivity of the self-enhancement measure to the modesty response. Cross-Cultural Research, 36, 73-95.

Leslie, J. B., \& Fleenor, J. W. (1998). Feedback to managers: A review and comparison of multi-rater instruments for management development. Greensboro, NC: Center for Creative Leadership.

Lombardo, M. M., \& McCauley, C. D. (1994). Benchmarks: A manual and trainer's guide. Greensboro, NC: Center for Creative Leadership.

Lombardo, M. M., McCauley, C. D., McDonald-Mann, D., \& Leslie, J. B. (1999). Benchmarks: Developmental reference points. Greensboro, NC: Center for Creative Leadership.

Mabe, P., \& West, S. (1982). Validity of self-evaluation of ability: A review and meta-analysis. Journal of Applied Psychology, 67, 280-296.

Matsumoto, T. (2004). Learning to "do time" in Japan: A study of U.S. interns in Japanese organizations. International Journal of CrossCultural Management, 4, 19-37.

McCall, M., \& Lombardo, M. (1983). Off the track: Why and how successful executives get derailed (Tech. Rep. No. 21). Greensboro, NC: Center for Creative Leadership.

McCauley, C. D., \& Lombardo, M. (1990). Benchmarks: An instrument for diagnosing managerial strengths and weaknesses. In K. E. Clark \& M. B Clark (Eds.), Measures of leadership. West Orange, NJ: Leadership Library of America

Millman, J., Taylor, S., \& Czaplewski, A. (2002). Cross-cultural perfor- 
mance feedback in multinational enterprises. Human Resource Planning, 25, 29-43.

Morrison, A. M., White, R. P., \& Van Velsor, E. (1987). Breaking the glass ceiling: Can women reach the top of America's largest corporations? Reading, MA: Addison-Wesley.

Muthén, L., \& Muthén, B. (2006). Mplus (Version 4.0) [Computer software]. Los Angeles: Author.

Ostroff, C., Atwater, L., \& Feinberg, B. (2004). Understanding self-other agreement: A look at rater and ratee characteristics, context, and outcomes. Personnel Psychology, 57, 333-375.

Samovar, L. A., Porter, R. E., \& McDaniel, E. R. (2006). Intercultural communication: A reader. Belmont, CA: Wadsworth.

Schneider, S., \& Barsoux, J. (1997). Managing across cultures. London: Prentice Hall Europe.

Shipper, F., Hoffman, R., \& Rotondo, D. (2007). Does the 360 degree feedback process create actionable knowledge equally across cultures? Academy of Management Learning and Education, 6, 33-50.

Snijders, T. A., \& Bosker, R. J. (1999). Multilevel analysis: An introduction to basic and advanced multilevel modeling. Thousand Oaks, CA: Sage.

Spangler, M. (2003). Review of Benchmarks [revised]. In B. S. Plake, J. Impara, \& R. A. Spies (Eds.), The fifteenth mental measurements yearbook (pp. 124-126). Lincoln, NE: Buros Institute of Mental Measurements.

Sully de Luque, M., \& Sommer, S. (2000). The impact of culture on feedback-seeking behavior: An integrated model and propositions. Academy of Management Review, 25, 829-849.

Ting-Toomey, S. (1999). Communicating across cultures. New York: Guilford.
Triandis, H. C., McCusker, C., \& Hui, C. H. (1990). Multimethod probes of individualism and collectivism. Journal of Personality and Social Psychology, 59, 1006-1020.

Tsui, A., Nifadkar, S., \& Ou, A. (2007). Cross-national, cross-cultural organizational behavior research: Advances, gaps, and recommendations. Journal of Management, 33, 426-478.

Wohlers, A., Hall, M., \& London, M. (1993). Subordinates rating managers: Organizational and demographic correlates of self/subordinate agreement. Journal of Occupational and Organizational Psychology, 66, 263-275.

Wohlers, A., \& London, M. (1989). Ratings of managerial characteristics: Evaluation difficulty, co-worker agreement, and self-awareness. Personnel Psychology, 42, 235-261.

Xie, J., Chen, Z., \& Roy, J. (2006). Cultural and personality determinants of leniency in self-rating among Chinese people. Management and Organization Review, 2, 181-208.

Yammarino, F., \& Atwater, L. (1993). Understanding self-perception accuracy: Implications for human resource management. Human Resource Management, 32, 231-247.

Yuki, M., Maddux, W., Brewer, M., \& Takemura, K. (2005). Crosscultural differences in relationship and group based trust. Personality and Social Psychology Bulletin, 31, 48-62.

Zedeck, S. (1995). Review of Benchmarks. In J. Conoley, \& J. Impara (Eds.), The twelfth mental measurements yearbook (Vol. 1, pp. 128 129). Lincoln, NE: Buros Institute of Mental Measurements.

Received February 21, 2008 Revision received October 6, 2008 Accepted October 14, 2008 